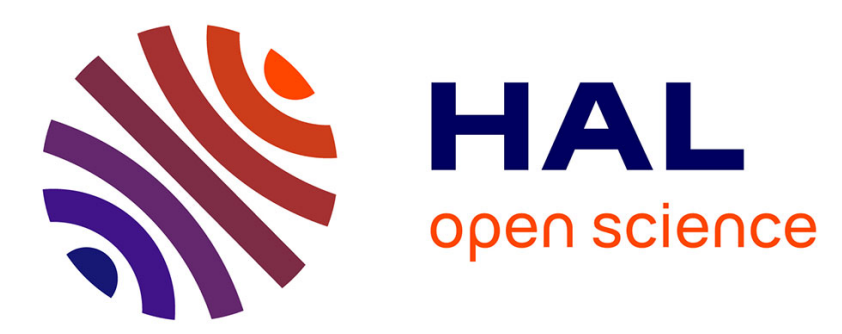

\title{
Anti-adhesion and antiproliferative cellulose triacetate membrane for prevention of biomaterial-centred infections associated with
}

Clara I. Extremina, A. Freitas Da Fonseca, Pedro L. Granja, António P. Fonseca

\section{To cite this version:}

Clara I. Extremina, A. Freitas Da Fonseca, Pedro L. Granja, António P. Fonseca. Anti-adhesion and antiproliferative cellulose triacetate membrane for prevention of biomaterial-centred infections associated with. International Journal of Antimicrobial Agents, 2009, 35 (2), pp.164. 10.1016/j.ijantimicag.2009.09.017 . hal-00556370

\section{HAL Id: hal-00556370 https://hal.science/hal-00556370}

Submitted on 16 Jan 2011

HAL is a multi-disciplinary open access archive for the deposit and dissemination of scientific research documents, whether they are published or not. The documents may come from teaching and research institutions in France or abroad, or from public or private research centers.
L'archive ouverte pluridisciplinaire HAL, est destinée au dépôt et à la diffusion de documents scientifiques de niveau recherche, publiés ou non, émanant des établissements d'enseignement et de recherche français ou étrangers, des laboratoires publics ou privés. 


\section{Accepted Manuscript}

Title: Anti-adhesion and antiproliferative cellulose triacetate membrane for prevention of biomaterial-centred infections associated with Staphylococcus epidermidis

Authors: Clara I. Extremina, A. Freitas da Fonseca, Pedro L. Granja, António P. Fonseca

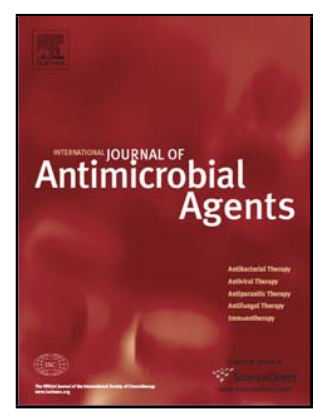

PII: S0924-8579(09)00440-3

DOI:

Reference: doi:10.1016/j.ijantimicag.2009.09.017

To appear in: International Journal of Antimicrobial Agents

Received date: $\quad 20-5-2009$

Revised date: $\quad 30-8-2009$

Accepted date: $\quad$ 8-9-2009

Please cite this article as: Extremina CI, Fonseca AF, Granja PL, Fonseca AP, Anti-adhesion and antiproliferative cellulose triacetate membrane for prevention of biomaterial-centred infections associated with Staphylococcus epidermidis, International Journal of Antimicrobial Agents (2008), doi:10.1016/j.ijantimicag.2009.09.017

This is a PDF file of an unedited manuscript that has been accepted for publication. As a service to our customers we are providing this early version of the manuscript. The manuscript will undergo copyediting, typesetting, and review of the resulting proof before it is published in its final form. Please note that during the production process errors may be discovered which could affect the content, and all legal disclaimers that apply to the journal pertain. 


\section{Anti-adhesion and antiproliferative cellulose triacetate membrane for prevention of biomaterial-centred infections associated with Staphylococcus epidermidis}

Clara I. Extremina ${ }^{a, b, \star}$, A. Freitas da Fonseca ${ }^{c}$, Pedro L. Granja ${ }^{b}$, António P. Fonseca $^{\mathrm{a}, \mathrm{d}}$

${ }^{a}$ REQUIMTE, Faculdade de Farmácia, Universidade do Porto, Rua Aníbal Cunha 164, 4050-047 Porto, Portugal

b INEB-Instituto de Engenharia Biomédica, Universidade do Porto, Rua do Campo Alegre 823, 4150-180 Porto, Portugal

c Instituto Piaget, Escola Superior de Saúde, Alameda Jean Piaget, Gulpilhares, 4405-678 Vila Nova de Gaia, Portugal

${ }^{d}$ Faculdade de Medicina da Universidade do Porto, Alameda Prof. Hernâni Monteiro, 4200-319 Porto, Portugal

ARTICLE INFO

Article history:

Received 20 May 2009

Accepted 8 September 2009

Keywords:

Staphylococcus epidermidis

Adhesion

Antimicrobial agents 
Cellulose triacetate

* Corresponding author. Tel.: +35122 207 8972; fax: +35122200 3977.

E-mail address: extremina@gmail.com (C.I. Extremina). 


\section{ABSTRACT}

The initial step in preventing biomaterial-associated infections consists of preventing bacterial adhesion to the device surface. One possible approach is the design of antibiotic-releasing biomaterials. Cellulose triacetate (CTA) membranes with the antibiotic imipenem (IPM) entrapped (CTA-IPM) were prepared. The material was characterised in terms of surface morphology by scanning electron microscopy, surface free energy of interaction and X-ray photoelectron spectroscopy (XPS). Antibiotic release studies were also performed. In vitro adhesion of Staphylococcus epidermidis RP62A to CTA-IPM was investigated using a modified microtitre plate assay, and the antibacterial activity of the CTA-IPM membrane was assessed by a modified Kirby-Bauer test, which showed effective entrapment of the antibiotic as confirmed by XPS and hydrophilicity assays. Release studies showed that this drug-polymer conjugate serves as an adequate reservoir for sustained release of IPM over a period of $71 \mathrm{~h}$ at an effective bacteriostatic concentration. Moreover, bacterial adhesion tests showed a statistically significant decrease in the adhesion of $S$. epidermidis RP62A to CTA-IPM compared with its adhesion to CTA alone. The present innovative approach is capable of providing a membrane with antiadhesive and antiproliferative properties, thus encouraging in vivo studies to provide a better simulation of the clinical situation. 


\section{Introduction}

There has been an increase in the use of biomedical materials in modern medicine, however a major drawback is biomaterial-centred infections (BCls) that are difficult to eradicate with antibiotics [1]. Treatment of $\mathrm{BCls}$ is complicated as the resistance of microorganisms to antibiotics is higher in the biofilm phenotype than in their planktonic counterparts $[1,2]$. As a consequence, and when possible, the only solution is to remove the infected implant resulting in a considerable increase in cost and patient suffering [3]. It is thus important to prevent $\mathrm{BCl}$ by avoiding bacterial adhesion and biofilm formation, which can be achieved by application of antimicrobial agents near the biomaterial surface. A possible means is the design of antibiotic-releasing biomaterials. Examples are gentamicin-loaded bone cements and silver-loaded catheters [4]. The device surface must be a matrix that serves as a reservoir for a large amount of drug and that should be capable of releasing the drug over time in appropriate quantities. Cellulose is a renewable and biodegradable natural polymer that presents excellent properties for use as a biomedical material, namely its nontoxicity, high hydrophilicity and some stability to temperature and $\mathrm{pH}$ variation [5]. Elam et al. [6] described the use of cellulose derivatives as possible coatings for polytetrafluoroethylene (PTFE), and Fonseca et al. [7] reported a chemical modification of cellulose acetate by both deacetylation and phosphorylation that decreased bacterial adhesion.

Tienam (imipenem and cilastatin sodium) is a broad-spectrum $\beta$-lactam antibiotic that is very soluble in water and methanol [8] and is effective against Staphylococcus epidermidis, a microorganism responsible far $n \operatorname{lnrnn} n$ numhnr $n f$ 
infections affecting medical devices. The aim of this research was to develop biomaterial surfaces with anti-adhesive and antiproliferative surface properties through the entrapment and subsequent sustained release of an antimicrobial agent.

\section{Materials and methods}

\subsection{Bacteria storage and growth}

The strains S. epidermidis RP62A (ATCC 35984) and M187-Sn3, an isogenic mutant of M187, were a generous gift from Gerald B. Pier (Harvard Medical School, Boston, MA). Bacteria were stored at $-70^{\circ} \mathrm{C}$ in brain-heart infusion medium (Merck, Darmstadt, Germany) containing 20\% glycerol. Staphylococcus epidermidis was routinely grown at $37^{\circ} \mathrm{C}$ on tryptic soy agar (TSA) (Difco, Sparks, MD) or in tryptic soy broth (TSB) (Difco) [9].

\subsection{Antibiotic}

A stock solution of the antibiotic imipenem (IPM) (Tienam; Merck Sharp \& Dohme, Darmstadt, Germany) was prepared in accordance with the recommendations of the Clinical and Laboratory Standards Institute [8].

\subsection{Preparation of cellulose triacetate (CTA) membranes}

CTA (Eastman Chemical Company, Capelle aan den IJssel, The Netherlands) was dissolved in chloroform/methanol (9:1 vol..\%) to form a $2 \%$ solution [10]. Films were cast onto glass dishes. A $7 \mathrm{~mL}$ polymer solution was poured into 
each dish (diameter $90 \mathrm{~mm}$ ) and the dish was then heated in an incubator at 20 ${ }^{\circ} \mathrm{C}$. Following evaporation of the solvent, thin films were obtained and used for further investigation after $24 \mathrm{~h}$.

\subsection{Entrapment of imipenem on cellulose triacetate membranes}

CTA and IPM powders were mixed and then dissolved in chloroform/methanol to form a $2 \%$ solution of CTA [10] with a concentration of IPM of $512 \mu \mathrm{g} / \mathrm{mL}$. The membranes were then prepared according to Section 2.3.

\subsection{Characterisation of the material surfaces}

\subsubsection{Structural characterisation: $X$-ray photoelectron spectroscopy (XPS)}

Survey spectra and high-resolution spectra for the $\mathrm{C} 1 \mathrm{~s}, \mathrm{O} 1 \mathrm{~s}$ and $\mathrm{N}$ 1s regions were obtained with a VG Scientific ESCALAB200 A spectrometer (Thermo VG Scientific, East Grinstead, UK) using Mg K $\alpha$ X-ray radiation as the excitation source. The emitted photoelectrons were analysed at a $55^{\circ}$ take-off angle from the horizontal surface plane for all analyses. Element atomic percentages were calculated from the integrated intensities of the XPS peaks, taking into account the atomic sensitivity factors of the instrument data system.

\subsubsection{Surface free energy determination}

Contact angle measurements were performed as previously described by Amaral et al. [11] using water, diiodomethane and glycerol (4 $\mu \mathrm{L})$ [7]. The timedependent measurements were taken for a period of $100 \mathrm{~s}$ and the 
experimental contact angles were extrapolated to time zero. A minimum of five drops were made per sample type in at least three different samples. The contact angle values were used to calculate the surface free energy of interaction between surface and water $\left(\Delta G_{s w s}^{T O T}\right)$ and the surface free energy of interaction between the bacteria and the material $\left(\Delta G_{b w s}^{T O T}\right)$.

\subsubsection{Surface morphology by scanning electron microscopy (SEM)}

The surface morphology of the disks was examined by SEM with a scanning electron microscope JEOL model JSM-6301F (JEOL Ltd., Tokyo, Japan) equipped with a Noran-Voyager energy dispersive spectroscope (Noran Instruments Inc., Middleton, WI) in CEMUP (Porto, Portugal). The samples were sputtered-coated with gold (JEOL JFC 1100 ion sputting device).

\subsection{Imipenem release studies}

The CTA-IPM membranes were immersed in a saline solution for 4260 min (71

h) to release the antibiotic adsorbed. Each assay was performed in triplicate. Samples were collected throughout the time of study and measured using ultraviolet (UV) spectroscopy at $298 \mathrm{~nm}$. A calibration curve was first obtained and its use was restricted to the linear part, which followed Beer's law $(A=a c l)$, where $A$ is the absorbance, $c$ is the concentration, $a$ is a proportionality constant related to the solution being tested (known as absorptivity) and / is the path length, which is constant and in this case equal to 1 [12], so that the concentration of IPM in solution could be determined. The adsorption of IPM was studied in saline solution. A UV spectrum of this solution was drawn from 
$200 \mathrm{~nm}$ to $1100 \mathrm{~nm}$ to determine the absorbance peak. For each concentration, three samples were collected.

\subsection{Bacterial adhesion assay}

In the adhesion assay, the strains RP62A and M187-Sn3 were incubated in 10 $\mathrm{mL}$ of TSB inoculated with bacteria grown on TSA plates not older than 2 days and were grown for $18 \pm 2 \mathrm{~h}$ at $37^{\circ} \mathrm{C}$ at $150 \mathrm{rpm}$. Afterwards, $1 \mathrm{~mL}$ of each cell suspension was transferred to $150 \mathrm{~mL}$ of fresh TSB, which was incubated for 18 $\pm 2 \mathrm{~h}$ at $37^{\circ} \mathrm{C}$ at $150 \mathrm{rpm}$. The protocol developed by Fonseca et al. [2] for the adhesion assay was modified and adapted. Bacteria were washed twice in saline solution $(0.9 \% \mathrm{NaCl}$ prepared in distilled water), centrifuged for $15 \mathrm{~min}$ at $1000 \times g$ and re-suspended in phosphate-buffered saline at a standard inoculum corresponding to ca. $10^{8}$ colony-forming units (CFU)/mL.

The CTA and CTA-IPM disks were placed in 24-well polystyrene microtitre plates. One millilitre of the bacteria inoculum was added to the wells of sterile microtitre plates with or without disks. Negative controls were obtained by placing the disks in saline solution without bacterial cells, and sterile controls were obtained by placing the disks in fresh TSB medium without bacterial suspension. The plates were incubated for $2 \mathrm{~h}$ at $37^{\circ} \mathrm{C}$. Following incubation, the microtitre plates were rinsed and adhesion was quantified according to a method previously described by Fonseca et al. [2]. Each assay was performed in triplicate and repeated three times. 


\subsection{Kirby-Bauer test}

The antibacterial activity of CTA and CTA-IPM was assessed in vitro by a modified Kirby-Bauer test. To this aim, the disks were placed in Petri plates containing Mueller-Hinton agar (Difco) and seeded with $10^{8} \mathrm{CFU} / \mathrm{mL}(0.5$ McFarland) of S. epidermidis RP62A. Following incubation at $37^{\circ} \mathrm{C}$ for $18 \mathrm{~h}$, the bacterial growth inhibition zone around the disks was analysed [3].

\subsection{Statistical analyses}

All the assays were compared using one-way analysis of variance (ANOVA) by applying Levene's test of homogeneity of variances, Tukey multiplecomparisons test and the paired samples $t$-test using SPSS software (SPSS Inc., Chicago, IL). Differences were considered statistically significant at $P \leq$ 0.05 .

\section{Results}

\subsection{X-ray photoelectron spectroscopy}

No detectable changes were observed by attenuated total reflection-Fourier transform infrared spectroscopy (ATR-FTIR) between CTA and CTA- IPM, thus the membranes were analysed by XPS. The survey spectrum of CTA showed that carbon $(\mathrm{C})$ and oxygen $(\mathrm{O})$ were present in the film and that there was no contamination. The spectrum is similar to typical XPS spectra obtained for CTA [13] (Table 1A). 
In the case of CTA-IPM membranes, the atomic percentages of $\mathrm{C}, \mathrm{O}$ and nitrogen $(\mathrm{N})$ obtained by high-resolution XPS spectra were $66.8 \%, 32.7 \%$ and $0.4 \%$, respectively (Table $1 \mathrm{~A}$ ). The components of the $\mathrm{C} 1 \mathrm{~s}$ spectrum and $\mathrm{O} 1 \mathrm{~s}$ spectrum are available in the literature [13].

The peaks found in the literature for the components of $\mathrm{N}$ spectrum correspond to $\mathrm{NH}_{2}$ (peak 2) and $\mathrm{NH}$ (peak 1) [13].

\subsection{Surface free energy determination}

Table 1B shows the contact angle values reported in the literature [7] for the different strains assayed with three different liquids, two polar (water and glycerol) and one apolar (diiodomethane).

Table 1B shows that the non-capsulated strain M187-Sn3 showed a $\Delta G_{b w}^{T O T}$ value more positive than the capsulated strain RP62A, which indicates higher hydrophilicity [9]. Our data revealed that the presence of IPM on CTA membranes increased the $\Delta G_{b w s}^{T O T}$ value $\left({ }^{\Delta G_{b w s}^{T O T}}=11.63\right.$ for CTA and 22.33 for CTA-IPM). There were no significant differences between strains with different phenotypes ( ${ }^{\Delta G_{b w s}^{T O T}}=11.63$ for RP62A and 8.86 for M187-Sn3).

\subsection{Imipenem release studies}

The results fit the linear part of the curve, which is described by the equation $A$ $=0.0162 c$, and a correlation factor of 0.9087 was found. All the concentration 
results were based on this calibration curve. Fig. 1 illustrates the amount of IPM released by CTA-IPM measured at $298 \mathrm{~nm}$ and shows a gradual decrease in the IPM released from CTA until 1365 min, after which there was stabilisation in the release values until $4260 \mathrm{~min}$.

\subsection{Bacterial adhesion assay}

As a consequence of previous results [7], we selected the strain with higher adhesion abilities (RP62A) for further studies. There was a significant decrease in the adhesion of $S$. epidermidis RP62A to CTA-IPM $(0.075 \pm 0.016)$ compared with its adhesion to CTA $(0.132 \pm 0.037)$. Adhesion of $S$. epidermidis RP62A to CTA and CTA-IPM is not thermodynamically favoured, since the total free energy of interaction between the bacteria, material and water is positive. Nevertheless, the free energy of interaction $\Delta G_{b w s}^{T O T}$ is more positive for CTAIPM.

\subsection{Kirby-Bauer test}

Fig. 2A shows the inhibition zones of $S$. epidermidis RP62A after growth in the presence of CTA or CTA-IPM membranes. No inhibition zone was caused by the CTA disk. On the other hand, the inhibition zone caused by the CTA-IPM disk was $3.9 \mathrm{~cm}$.

\subsection{Scanning electron microscopy}

Fig. 2B,C shows SEM images of the membranes with $S$. epidermidis RP62A adhered after the adhession assay. This figure illustrates $t^{1}-\ln \ldots+\cdots:-1$ dh 
pattern on the CTA surface as well as minor adhesion to the material incorporating the antibiotic (CTA-IPM), which is in accordance with the values obtained in the adhesion assay. The formation of aggregates found on the CTA surface is not observed on the CTA-IMP membrane surface.

\section{Discussion}

The anti-adhesive and antiproliferative properties of a CTA membrane impregnated with IPM were assessed.

ATR-FTIR was initially used for surface characterisation, but low efficacy was observed in detecting surface modifications between CTA and CTA-IPM. XPS was therefore used to detect nitrogen compounds. Since no significant shifts occurred in the positions of the peaks, there is no evidence of any chemical interaction between CTA and IPM. The hydrophobicity of the materials was also assessed. A positive $\Delta G_{s w s}^{T O T}$ value indicates a decrease in the available energy for adhesion and this occurs when the bacteria adhere to CTA or CTA-IPM disks. The concentration of IPM during whole the release assay was supraminimum inhibitory concentration (MIC), which is in accordance with results described previously by Yigong et al. [14]. In fact, the IPM concentration near the surface is probably bactericidal and the results of the Kirby-Bauer test confirm that IPM is functional after entrapment on the CTA membrane, thus confirming the antiproliferative character of the CTA-IPM membranes. These data confirm CTA as an adequate reservoir for IPM entrapment and its 
subsequent sustained release over an appropriate period of time at an effective concentration.

The presence of a significant amount of antibiotic released from the material during the $2 \mathrm{~h}$ of the adhesion assay (Fig. 1) may kill or affect the adhesion and biofilm formation abilities of the $S$. epidermidis strain, as can be seen by SEM comparing the bacterial adhesion patterns on the CTA and CTA- IMP surfaces (Fig. 2B,C). Adhered bacteria are probably not viable or have altered morphophysiological properties and thus are not capable of forming biofilm. Martínez-Martínez et al. [15] found that subinhibitory concentrations of $\beta$ lactams affect the production of slime, the surface hydrophobicity and the adhesion of $S$. epidermidis. These findings may also explain the reduction in adhesion ability of the strain studied in the presence of IPM released from CTA membranes.

Staphylococcus epidermidis RP62A is less hydrophilic than M187-Sn3 (Table 1B) and as a consequence it is expected to present lower adhesion values to more hydrophilic surfaces, which is the case for the CTA-IPM membrane. From the thermodynamic approach, it was observed that CTA is a hydrophobic surface, therefore promoting higher adhesion of a less hydrophilic strain. The lower bacterial adhesion to CTA-IPM membrane can be possibly explained by the change in hydrophilicity of the surface caused by IPM entrapment in conjunction with the effect of IPM itself released during the process of adhesion, as well as by the change in surface morphology caused by the entrapment of IPM. 
The main purpose of the present work was to develop strategies to entrap antibiotics on medical device surfaces, providing release while maintaining the bulk properties of the material. By using the present approach, it seems possible to obtain an adequate medical device surface with CTA-IPM with antiadhesive and antiproliferative properties.

\section{Acknowledgments}

The authors are grateful to Isabel Amaral (INEB, Porto, Portugal) for assistance with the contact angle equipment, to Manuela Bras (INEB) for assistance with FTIR and to Carlos Sá and Daniela Silva (CEMUP) for their assistance in XPS and SEM analyses, respectively. Gerald B. Pier (Harvard Medical School, Boston, MA) is thanked for the kind gift of strains S. epidermidis RP62A and M187-Sn3.

\section{Funding}

None.

\section{Competing interests}

None declared.

\section{Ethical approval}

Not required. 


\section{References}

[1] Darouiche RO. Treatment of infections associated with surgical implants. N Engl J Med 2004;350:1422-9.

[2] Fonseca AP, Extremina C, Fonseca AF, Sousa JC. Effect of subinhibitory concentration of piperacillin/tazobactam on Pseudomonas aeruginosa. J Med Microbiol 2004;53:903-10.

[3] Donelli G, Francolini I, Piozzi A, Di Rosa R, Marconi W. New polymerantibiotic systems to inhibit bacterial biofilm formation: a suitable approach to prevent central venous catheter-associated infections. J Chemother 2002;14:501-7.

[4] Akiyama H, Okamoto S. Prophylaxis of indwelling urethral catheter infection: clinical experience with a modified Foley catheter and drainage system. $\mathrm{J}$ Urol 1979;121:40-2.

[5] Granja PL, Baquey C, Pouységu L, Bareille R, De Jéso B, Barbosa MA. Cellulose-based biomaterials for bone regeneration: hemi-synthesis and characterisation. In: Proceedings of Polymers in Medicine and SurgeryPIMS'96; Glasgow, UK; 1996. p. 73-80.

[6] Elam JH, Karlsson $\mathrm{CH}$, Nygren $\mathrm{H}$. Pre-adsorption of cellulose ether onto polymer surfaces: adsorption of adhesins and platelet activation. Biomaterials 1992;14:233-7.

[7] Fonseca AP, Granja PL, Nogueira JA, Oliveira DR, Barbosa MA. Staphylococcus epidermidis RP62A adhesion to chemically modified cellulose derivatives. J Mater Sci Mater Med 2001;12:543-8. 
[8] Clinical and Laboratory Standards Institute. Performance standards for antimicrobial susceptibility testing. Sixteenth informational supplement. Document M100-S16. Wayne, PA: CLSI; 2006.

[9] Vacheethasanee K, Temenoff JS, Higashi JM, Gary A, Anderson JM, Bayston $\mathrm{R}$, et al. Bacterial surface properties of clinically isolated Staphylococcus epidermidis strains determine adhesion on polyethylene. $\mathrm{J}$ Biomed Mater Res 1998;42:425-32.

[10] Bhat NV, Wavhal DS. Preparation of cellulose triacetate pervaporation membrane by ammonia plasma treatment. J Appl Polym Sci 2000;76:25865.

[11] Amaral IF, Granja PL, Melo Luis V, Saramago B, Barbosa MA. Functionalization of chitosan membranes through phosphorylation: atomic force microscopy, wettability, and cytotoxicity studies. J Appl Polym Sci 2006;102:276-84.

[12] Thomas MJK, Ando DJ. Ultraviolet and visible spectroscopy: analytical chemistry by open learning. New York, NY: Wiley; 1996.

[13] Beamson G, Briggs D, editors. High resolution XPS of organic polymers: the Scienta ESCA300 database. Chichester, UK: John Wiley \& Sons Ltd.; 1992.

[14] Yigong Ge, Wikler MA, Sahm DF, Blosser-Middleton RS, Karlowsky JA. In vitro antimicrobial activity of doripenem, a new carbapenem. Antimicrob Agents Chemother 2004;48:1384-96.

[15] Martínez-Martínez L, Pascual A, Giglio MI, Perea EJ. Effect of subinhibitory concentrations of $\beta$-lactams on the production of slime, surface 
hydrophobicity and adhesion of Staphylococcus epidermidis [in Spanish].

Enferm Infecc Microbiol Clin 1991;9:543-6. 
Fig. 1. Concentration of imipenem (IMP) incorporated by cellulose triacetate.

Fig. 2. (A) Bacterial inhibition zone performed by Kirby-Bauer test for cellulose triacetate (CTA) and CTA membranes with the antibiotic imipenem entrapped (CTA-IPM). (B,C) Scanning electron micrograph $(\times 500)$ of RP62A strain adhered to a CTA disk (B) and to a CTA-IPM disk (C). 


\section{Table 1}

(A) Positions and atomic percentage of species present, obtained by deconvolution of high-resolution X-ray photoelectron spectroscopy (XPS) spectra and (B) contact angle values, polar and apolar surface tension parameters and surface free energy of interaction

\section{(A)}

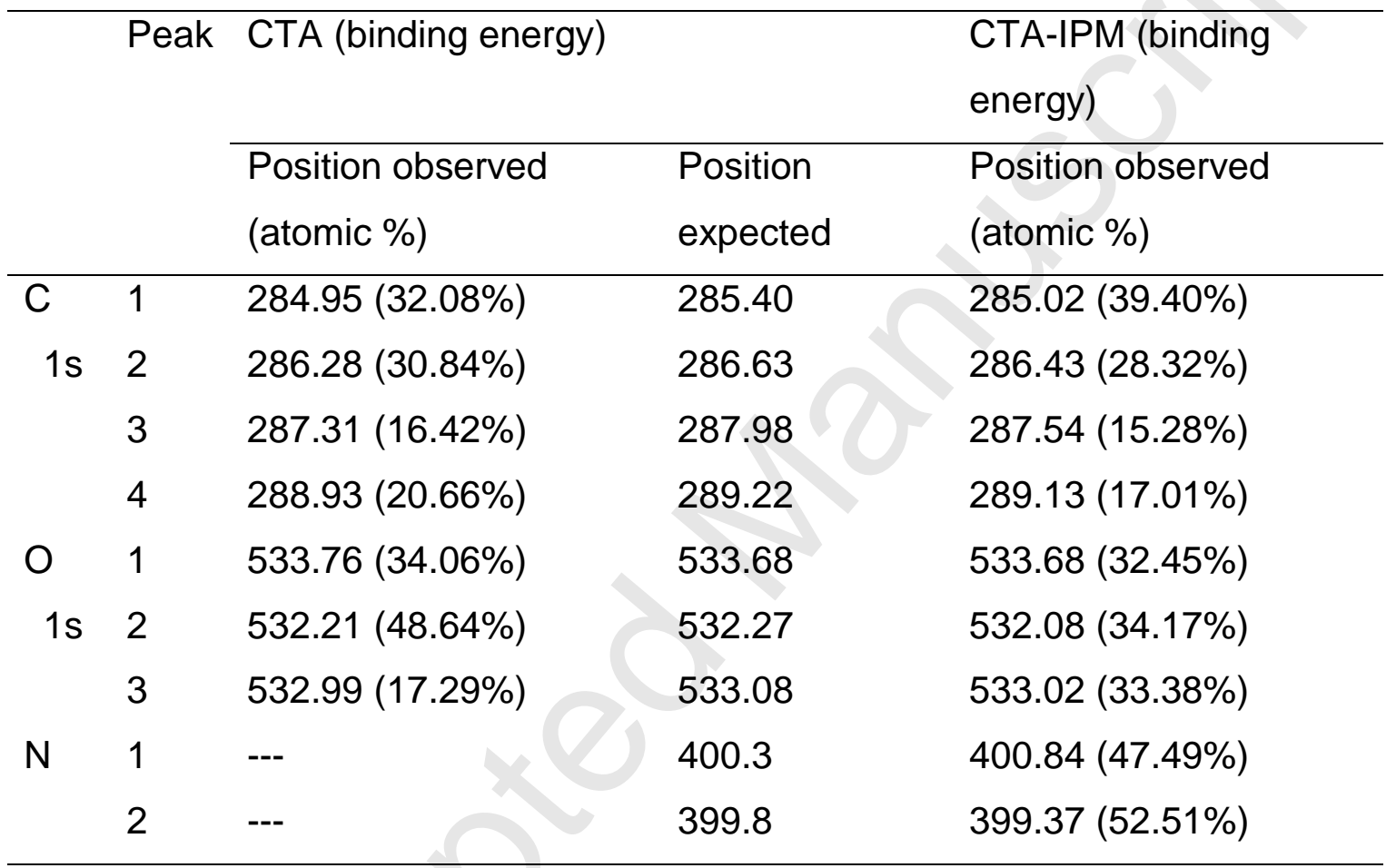

(B)

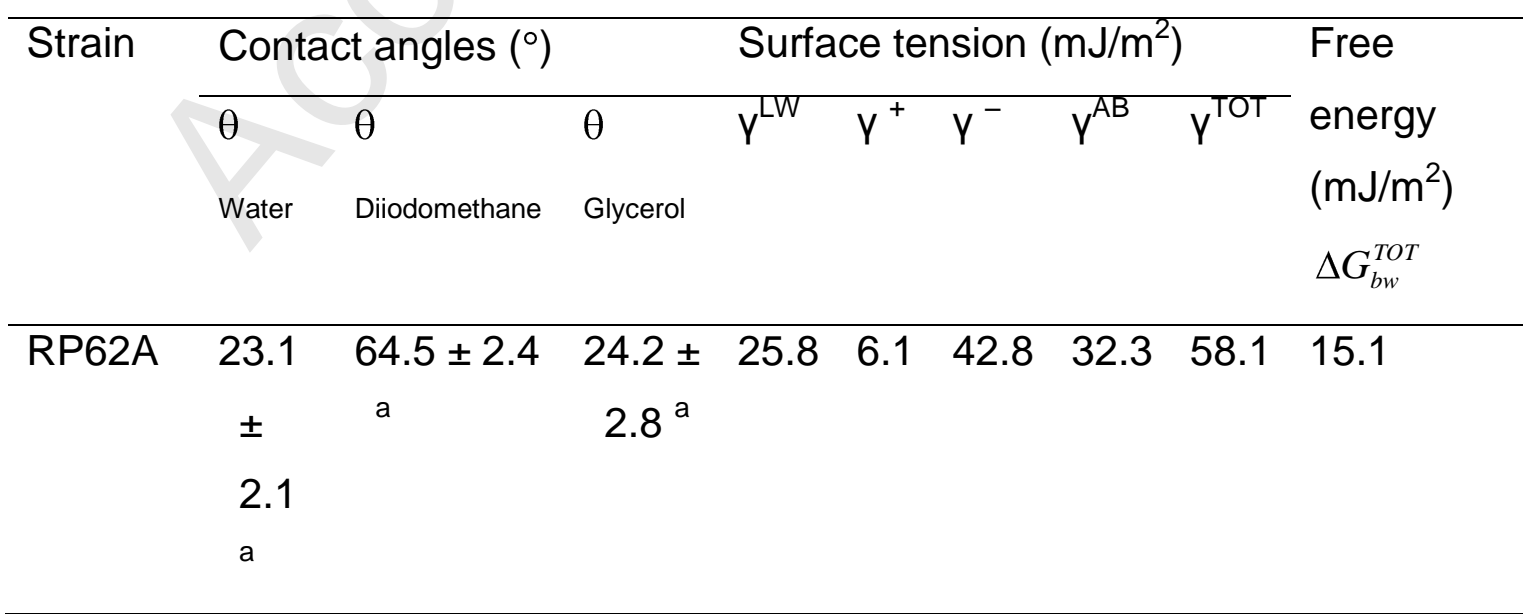




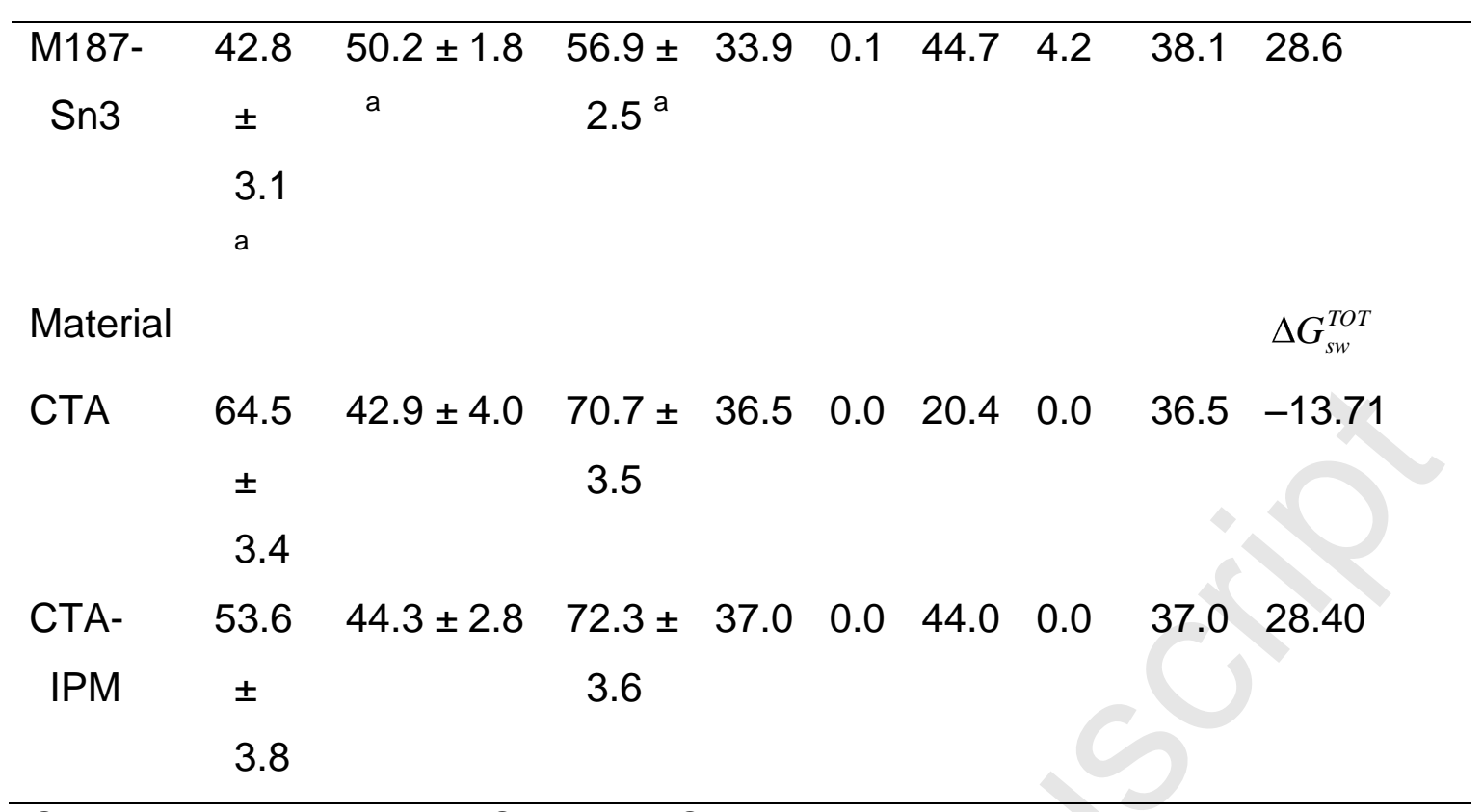

CTA, cellulose triacetate; CTA-IPM, CTA with the antibiotic imipenem

entrapped; C, carbon; O, oxygen; $\mathrm{N}$, nitrogen.

${ }^{a}$ Data published in Fonseca et al. [7]. 


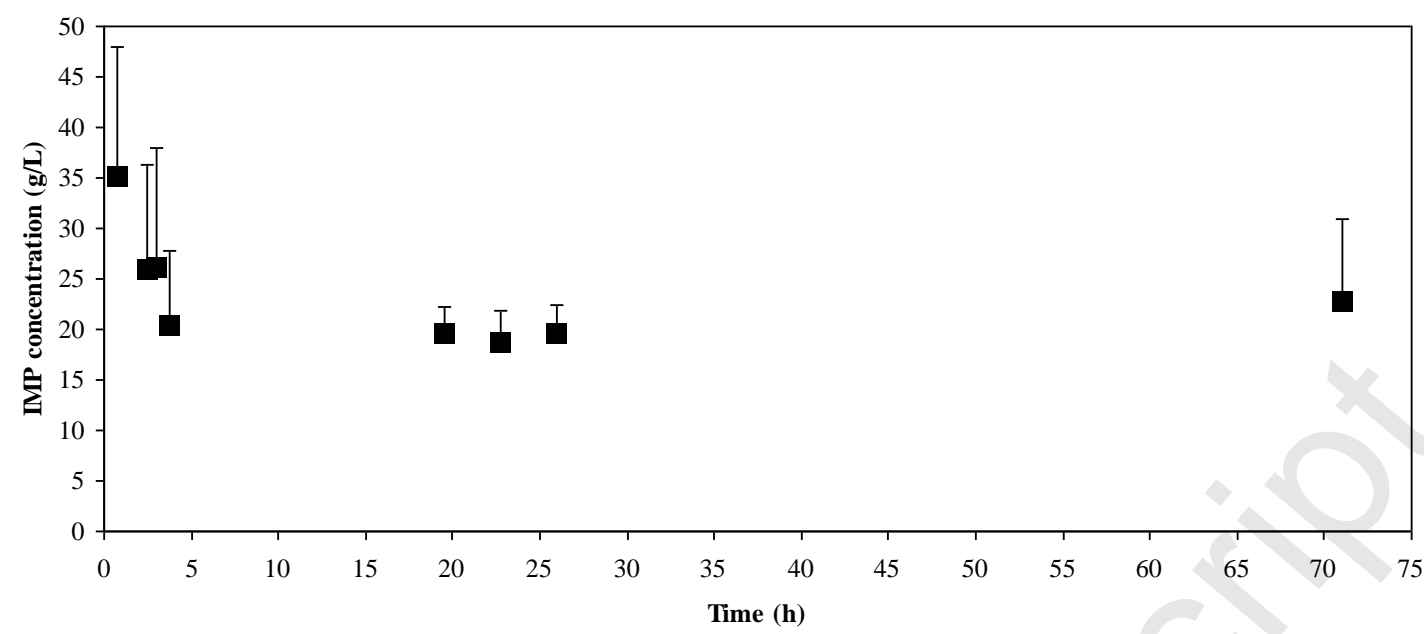


